\title{
HIPPOCAMPAL RESECTIONS IMPAIR ASSOCIATIVE LEARNING AND RECOGNITION MEMORY IN THE MONKEY ${ }^{1}$
}

\author{
HELEN MAHUT, ${ }^{2}$ STUART ZOLA-MORGAN, ${ }^{3}$ AND MARK MOSS ${ }^{4}$ \\ Department of Psychology, Northeastern University, Boston, Massachusetts 02115 \\ Received February 10, 1982; Revised May 24, 1982; Accepted May 26, 1982
}

\begin{abstract}
Damage to the hippocampus has been implicated in the permanent loss of memory in patients with medial temporal lobe resections. In two previous studies, it was established that bilateral ablations of the hippocampus in the monkey impaired performance on an associative learning task and on an object discrimination retention task. The two objectives of the present study were to assess the long term effects of hippocampal resections in the monkey and to extend the analysis of the effects of these resections to recognition memory.

Therefore, the performance of monkeys with either hippocampal ablations or fornix transections, sustained 5 years earlier, was compared (1) on a concurrent discrimination task-a previously unencountered associative learning task-and (2) on a nonmatching-to-sample recognition task with either delays interposed between the presentation of the sample object and the recognition trial or with lists of either 1-, 3-, 5-, or 10-object samples. Significant impairment on both tasks was found after hippocampal, but not after fornix, damage. Though monkeys in the hippocampal group were impaired on both delays and lists, the impairment was more severe on the lists, with abnormal sensitivity to pro- and retroactive interference as a possible source of difficulty. Thus, in parallel with clinical findings, ablations of the hippocampus in the nonhuman primate produce an enduring disruplion of memory.
\end{abstract}

When a severe and permanent loss of memory was found in patients after resections of medial temporal lobe structures which included the hippocampal formation, hippocampal gyrus, amygdala, and uncus (Scoville, 1954; Scoville and Milner, 1957; Penfield and Milner, 1958; Milner, 1972, 1974), damage to the hippocampus was strongly implicated in the deficit. In line with clinical findings, combined amygdalohippocampal ablations in nonhuman primates have been shown to impair selective

\footnotetext{
${ }^{1}$ We wish to thank Lucio Rehbein for his help with the experimental design and with some of the testing. We also thank Dr. Steve Harkins for his help with the statistical analyses. Dr. Douglas Rosene kindly gave us his material for a photograph of the fornix-fimbria system in a normal monkey. This work was supported by grants from the National Science Foundation (BNS 77-173112), Public Health Service, National Institute of Child Health and Human Development (HD 08135-04-05), and Department of Health and Human Services, Northeastern University (RR 07143 to H. M.).

${ }^{2}$ To whom correspondence should be addressed at Psychology Department, Mugar Building 409, Northeastern University, Huntington Avenue, Boston, MA 02115.

${ }^{3}$ Present address: Veterans Administration Hospital, University of California, School of Medicine, La Jolla, CA 92093.

${ }^{4}$ Present address: Department of Anatomy, Boston University School of Medicine, Boston MA 02118.
}

aspects of learning and memory capacities (Orbach et al., 1960; Correll and Scoville, 1965; Mahut, 1971; Mishkin, 1978; Mahut et al., 1979, 1981).

However, learning and retention deficits also can follow experimental lesions that are confined to the hippocampus. First, monkeys with bilateral resections of the hippocampal zone (Ammon's horn, dentate gyrus, and subicular complex), although not impaired in learning individual object discriminations, were impaired when discriminations between members of eight pairs of objects were taught concurrently until the animals learned to discriminate every pair (concurrent discrimination task). A more detailed analysis of performance revealed that they were abnormally susceptible to interpair interference (Moss et al., 1981). Second, on a task in which monkeys were asked, on alternate days, either to perform a reversal of an easy object discrimination learned the day before or to demonstrate retention of an object discrimination learned the day before, hippocampal ablations were followed by a selective deficit on retention but not on reversal days. In parallel with modality-nonspecific deficits found in patients with temporal lobe resections that included the hippocampus (Corkin, 1965), operated monkeys were impaired on the two tasks not only in the visual but also in the tactual modality (Mahut et 
al., 1981). Third, hippocampal ablations were followed by a deficit on a task which required the retention of easy object discriminations after either 1-, 24-, or 48-hr delays (Mahut et al., 1981).

The first two tests of memory were complex. The first task required the acquisition and retention of multiple object-reward associations in the presence of a great deal of pro- and retroactive interpair interference. The second task required the capacity to both maintain and readily abandon previously correct object-reward associations. However, the third task was neither contaminated by reversal requirements nor did it provide interpair interference. This made it easier to interpret the impaired performance of operated monkeys in terms of a deficit in retention of object-reward associations.

A novel method of assessing memory in nonhuman primates was introduced by Gaffan (1974): with a matching-to-sample technique, monkeys were trained to indicate whether they were able to discern, after a single previous presentation, a familiar (i.e., previously presented) from a novel (i.e., not previously presented) test object. In one version of the task, delays between familiarization with the sample object and its re-presentation with a novel one were increased from 10 to 70 and 130 sec. In another version, several sample objects were presented serially and each "list" was followed by matching trials of each list member with a novel object. Since, given a large pool of objects, several days would elapse before the same item was used again, the task approximated a trial-unique test of recognition memory. In many respects, Gaffan's (1974) task resembled, more than did other standard laboratory tasks, some of the clinical tests that reveal memory deficits in patients.

In a continued effort to define the role of the hippocampus in mediating memory, the main ohjective of the present study was to examine the effects of hippocampal resections on visual recognition memory using a modification of Gaffan's (1974) task.

At the same time, this approach was to provide an opportunity to clarify an earlier finding. The two groups of operated monkeys which were to participate in the present study had sustained either fornix transections or ablations of the hippocampal formation approximately 5 years earlier. In the intervening period, they had been tested, on three occasions separated by 1 year, on an object discrimination retention task with either 1-, 24-, or 48-hr delays (Mahut and Zola, 1976, 1977; Rehbein et al., 1980). On the last retest, the initial postoperative impairment became attenuated or was no longer present in individual monkeys. However, it was not possible to decide whether the improved performance was due to the effects of practice with one, and the same, task or whether it reflected a more general recovery of mnemonic function.

Accordingly, in the experiments to be described, the concurrent object discrimination task, known to reveal deficits after hippocampal, but not after fornix, damage, was chosen to serve as an unfamiliar test of associative learning (experiment 1). A modified version of Gaffan's (1974) task was to serve as an unfamiliar test of recognition memory (experiments $2 \mathrm{a}$ and $2 \mathrm{~b}$ ). The extent and pattern of the long term effects of the two types of damage to the hippocampal system on performance on two previously unencountered tests of learning and memory were of direct, additional interest.

\section{EXPERIMENT 1: CONCURRENT DiscRIMINATION TASK}

\section{Materials and Methods}

\section{Subjects}

The subjects were 19 experimentally sophisticated $\mathrm{Ma}$ caca mulatta (11 males and 8 females). The intended lesions were: bilateral section of the columns of the fornix $(\mathrm{Fx} ; n=8)$ and bilateral resection of the hippocampal formation $(\mathrm{H} ; n=7)$. Four additional monkeys served as an unoperated, control group. All animals were housed individually and were maintained on a diet of Purina Chow supplemented daily with vitamins and fruit. Feeding took place twice a day, with the last feeding occurring about $14 \mathrm{hr}$ before testing.

The monkeys were approximately 7 years old when the present study began. They had been tested previously on spatial and object reversal tasks and on an object discrimination retention task. They also had taken part, immediately prior to the present experiments, in a study in which they could indicate their preference for perceptual novelty in both visual and auditory modalities (ZolaMorgan et al., 1982).

\section{Surgery}

All operated monkeys were anesthetized intravenously ( $35 \mathrm{mg} / \mathrm{kg}$ of body weight) with Nembutal and aseptic surgery was performed in one stage. For fornix sections, a large dorsal craniotomy and a unilateral dural flap were followed by retraction of the medial aspect of the right hemisphere. This allowed us to make a longitudinal incision of the corpus callosum leading into the frontal horn of the opposite ventricle under direct vision through an operating microscope. The columns of the fornix then were raised and cut by means of a small hook at, or a slight distance behind, the foramen of Monro. For hippocampal resections, a large triangular craniotomy was made over the lateral portion of the temporal lobe. To permit exposure of the ventral surface of the brain, anastomotic veins were coagulated and the occipitotemporal convexity was retracted gently. The cortex and the underlying white matter just medial to the occipitotemporal sulcus were removed by suction. The exposed hippocampus then was aspirated with a 19 gauge sucker using the roof of the lateral ventricle as a guide.

\section{Histological verification of lesions}

After completion of the project, operated monkeys were killed with an overdose of Nembutal and the brains were perfused with $0.9 \%$ saline and $10 \%$ formalin. The brains were removed, blocked, photographed, dehydrated, and embedded in albumin. Frozen sections were cut at $30 \mu \mathrm{m}$ in the frontal plane, with every fourth section stained with the Weil stain for fibers and every fifth stained with cresyl violet for cellular Nissl substance.

Six of the 8 monkeys in the fornix group (Fx-1 to Fx-4, $\mathrm{Fx}-6$, and $\mathrm{Fx}-7)$ sustained complete bilateral sections of the fimbria-fornix system with resulting gliosis of the 

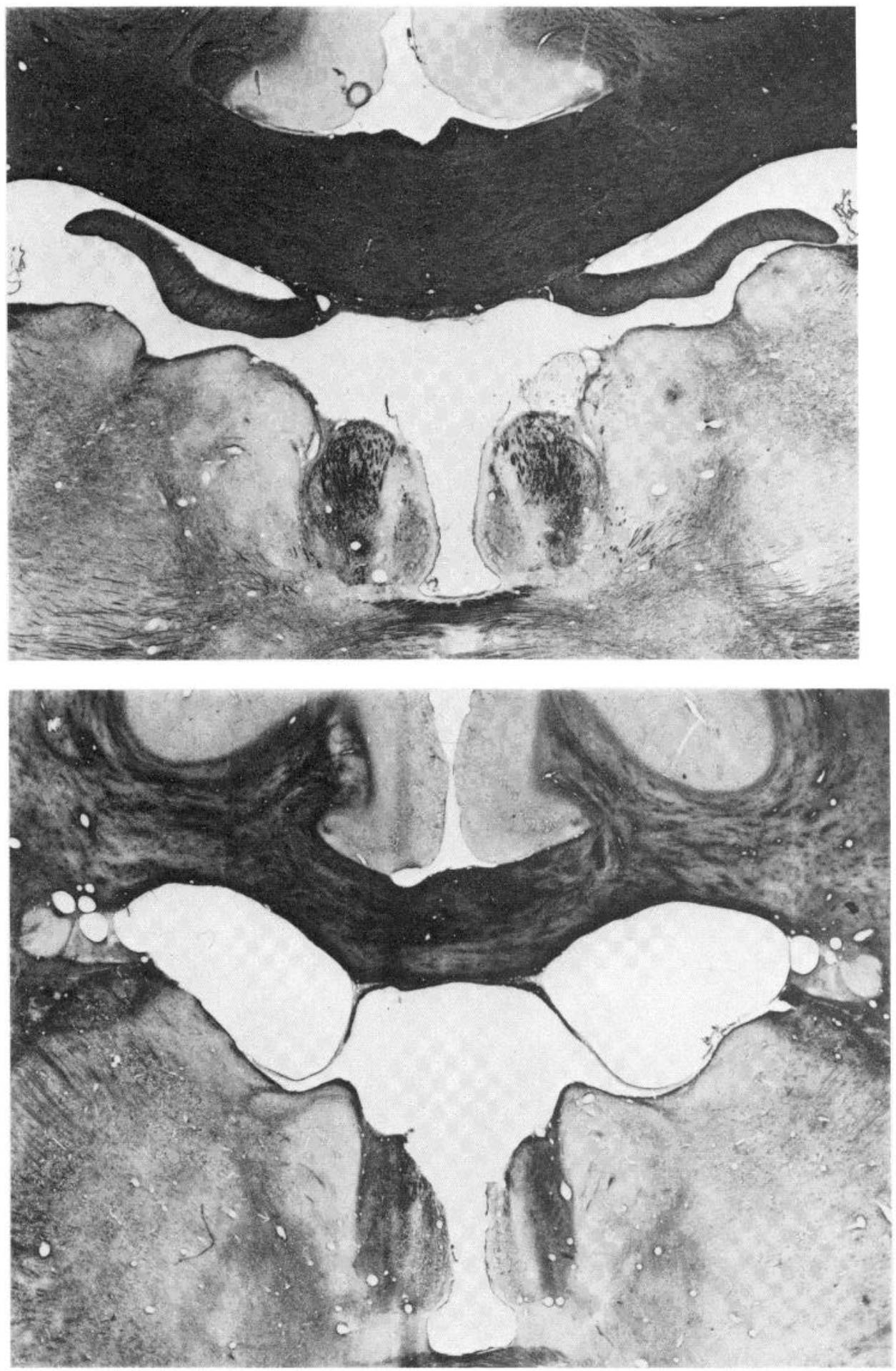

Figure 1. Top, Photograph of a normal fornix. Bottom, Degenerated fornix after a bilateral section at the supracommissural level (monkey Fx-1).

postcommissural fornix fibers. In 2 other monkeys, sections of the fornix were incomplete: in $\mathrm{Fx}-8$, bilateral section was restricted to the medial quarter of the fornix and Fx-9 sustained only a unilateral section in the right hemisphere. Due to a relatively caudal surgical approach, the supracommissural septum was intact in all monkeys with fornix sections. However, the frontocingulate bundle was interrupted in the right hemisphere in 4 of the 6 monkeys with complete transections of the fornix (Fx-2,
$-3,-4$, and -6 ) as well as in Fx-9, with a unilateral fornix section. A photograph of two representative brain sections in Figure 1 shows the fornix in a normal monkey and a degenerated fornix in one with a bilateral section at the supracommissural level.

Note. The 8 monkeys with intended fornix sections are coded from 1 to 9 , but monkey Fx-5 did not participate in the present study.

Five of the 7 monkeys with intended resection of the 
hippocampus sustained either total or near total bilateral removal of the hippocampal formation (Ammon's horn, dentate gyrus, and subicular complex). In the other $2(\mathrm{H}-$ 5 and $\mathrm{H}-6$ ), the anterior third of the hippocampus was spared in the right hemisphere, corresponding to levels A 7.5 to A 12.0 of Snider and Lee's (1961) atlas of the monkey brain.

All 7 monkeys had additional damage to extrahippocampal structures (Table III).

Area TF-TH of von Bonin and Bailey (1947). Bilateral, symmetrical damage was small in 4 monkeys (H-2, $-3,-4$, and -5 ), moderate (not exceeding $60 \%$ of its extent) in 2 ( $\mathrm{H}-1$ and $\mathrm{H}-6)$, and extensive in 1 (H-7-Am).

Inferotemporal neocortex (area TE of von Bonin and Bailey, 1947). Bilateral, symmetrical damage was small in 1 monkey (H-2) and moderate in the other (H-7-Am). Unilateral damage was moderate in $1(\mathrm{H}-3)$ and negligible in the remaining 4 monkeys.

Amygdala. In 2 monkeys ( $\mathrm{H}-2$ and $\mathrm{H}-3)$, damage was unilateral and small, limited to the caudal portion, and in $1(\mathrm{H}-7-\mathrm{Am})$, bilateral and symmetrical damage was moderate throughout its extent.

Entorhinal area. Extensive damage was sustained unilaterally by 2 monkeys (H-3 and $\mathrm{H}-2$ ) and bilaterally in 1 other (H-7-Am).

Temporal stem. The temporal stem was damaged bilaterally for a distance of 2 to $3 \mathrm{~mm}$ in $\mathrm{H}-2$ and H-7-Am and to the same extent but unilaterally in $\mathrm{H}-4$.

Detailed illustrations of representative lesions sustained by monkeys with hippocampal removals were given elsewhere ('Kola-Morgan et al., 1982). However, a representative radical, bilateral ablation of the hippocampus is illustrated in Figure 2 and cortical bilateral damage is illustrated in Figure 3.

After histological examination of the lesions, the following three groups of animals were constituted: groups $\mathrm{Fx}$ and $\mathrm{H}$, with 6 monkeys each, and group $\mathrm{C}$, with 4 normal, unoperated monkeys and 2 monkeys with either negligible or unilateral fornix damage ( $\mathrm{Fx}-8$ and $\mathrm{Fx}-9$ ). Monkey H-7-Am was the only animal to have sustained additional bilateral damage to both the amygdala and area $\mathrm{TE}$, and previous findings indicated that, at least on some tasks, combined amygdalohippocampal ablations (with or without area TE damage) may result in more severe behavioral deficits than would ablations confined to the hippocampal formation (Mahut, 1971; Mishkin, 1978; Mahut et al., 1981). Therefore, the data obtained by $\mathrm{H}-7-\mathrm{Am}$ were not included with the data obtained by monkeys in the hippocampal group but will be described and tabulated separately.

\section{Apparatus and procedure}

Detailed descriptions, given previously (Moss et al., 1981), can be summarized as follows: testing took place in a modified Wisconsin General Testing Apparatus. The experimenter sat behind a one-way screen facing the tray containing two food wells, $36 \mathrm{~cm}$ apart, center to center. Between trials, the tray was concealed from the monkeys by an opaque door. Eight pairs of junk objects were used. The pairs were presented in an intermingled fashion during each testing session so that all eight discriminations had to be learned simultaneously. Specifically, on each trial, one pair of objects was presented, and over

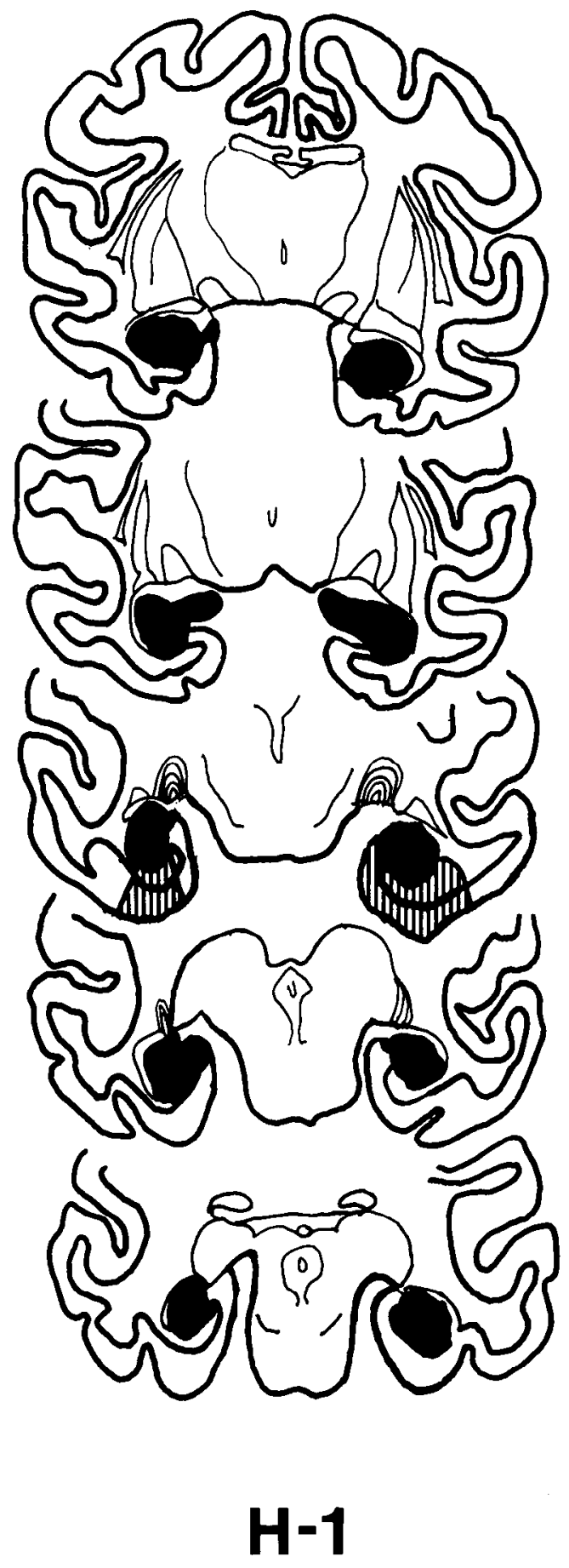

Figure 2. Representative coronal sections showing a radical bilateral ablation of the hippocampal formation. The solid black areas indicate the extent of damage to the hippocampal formation and the striped areas show the extent of extrahippocampal formation damage.

the course of each testing session of 40 trials, any given pair appeared 5 times. Raisins or small pieces of apple were used as reward for displacing the correct object, and using a noncorrection procedure, testing was continued until a learning criterion of 39 correct responses in 40 consecutive trials was met in one session or for a maximum of 1120 trials. 

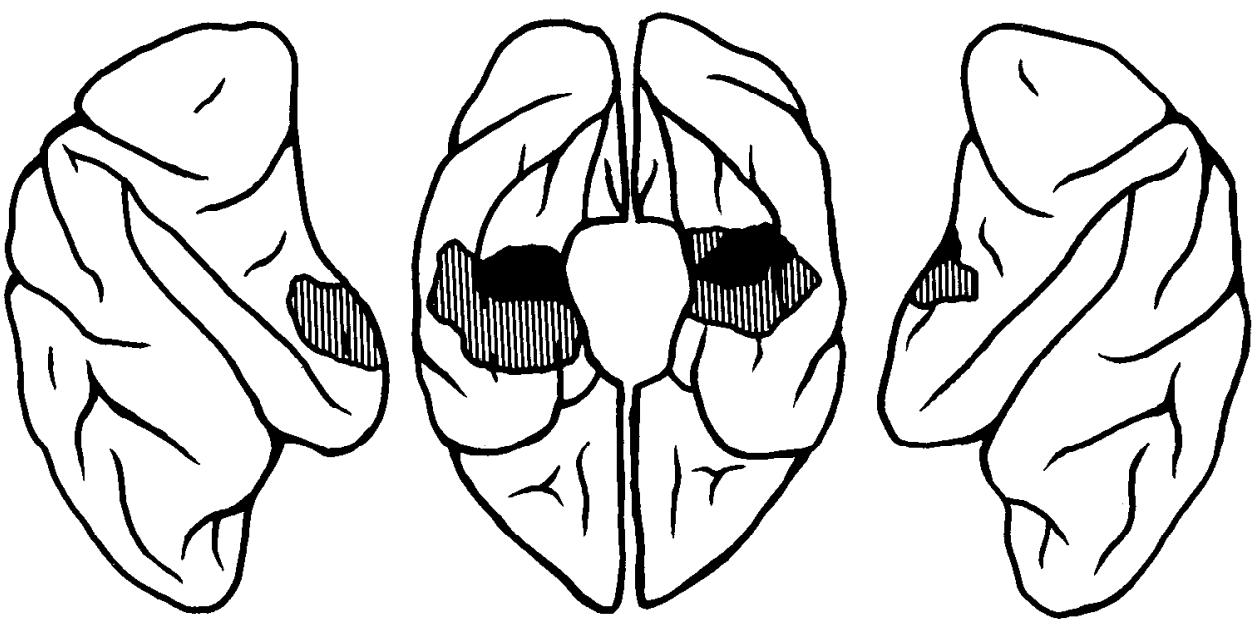

Figure 3. Composite tracings of the ventral and lateral aspects of the brain showing the smallest and largest damage to extrahippocampal cortical structures. The solid black areas indicate the extent of the smallest and the striped areas (including the solid black areas) show the extent of the largest bilateral lesions.

\section{Results}

Individual data for all monkeys are shown in Table I. Trial and error scores obtained by monkeys in group Fx were well within the normal range. In contrast, each monkey in group $\mathrm{H}$ obtained higher learning scores than did any of the monkeys in either group C or Fx. Monkey H-7-Am also obtained elevated trial and error scores.

To see at what point monkeys in group $\mathrm{H}$ began to experience more difficulty in learning successive pairs than did monkeys in group $\mathrm{C}$ or Fx, we noted the number of daily sessions required by monkeys in each group to learn their first, second, and each of the remaining six pairs (i.c., to make no more than 1 error on 2 consecutive days on any given pair). The data thus obtained were subjected, where appropriate, to Kruskal-Wallis one-way analyses of variance, followed by individual comparisons between groups using the Mann-Whitney $U$ test (Siegel, 1956).

The results of this analysis are illustrated in Figure 4. There were no significant differences among groups in the number of sessions (days) required to master the first four pairs. However, significant differences were found with the fifth $(H=6.01 ; p<0.05)$, sixth $(H=6.07 ; p<$ $0.05)$, seventh $(H=10.95 ; p<0.01)$, and eighth $(H=$ 9.64; $p<0.01$ ) pairs, respectively. Monkeys in group $\mathrm{H}$ required significantly more sessions than did monkeys in either group $\mathrm{C}$ or Fx to learn the fifth and sixth pairs ( $p$ values $<0.032$; one-tailed test) as well as the seventh and eighth pairs ( $p$ values $<0.001$; one-tailed test).

Summary. Monkeys with removal of the hippocampal formation, but not those with section of the fornix, were impaired significantly in learning eight discriminations presented concurrently. While four pairs were learned with relatively normal ease, the remaining four were learned at a significantly slower rate than by control monkeys or by those with fornix sections. No systematic relationship was found between the presence or absence of damage to extrahippocampal structures and the severity of the defect (Tables I and III). These findings em-
TABLE I

Experiment 1: Performance of monkeys with fornix sections and those with ablations of the hippocampal formation on the concurrent discrimination task

Animals in the hippocampal group are coded numerically for the extent of hippocampal removal, with low variability in size of the lesion for monkeys $\mathrm{H}-1$ to $\mathrm{H}-4$ and some unilateral sparing in $\mathrm{H}-5$ and $\mathrm{H}-6$. Monkeys within each group are ordered with respect to errors. In H-7Am, there was additional bilateral damage to the amygdala and anterior inferotemporal neocortex (area TE).

\begin{tabular}{ccc}
\hline Group & Trials & Errors \\
\hline Control $(n=6)$ & & \\
Normal & & \\
N-1 & 160 & 38 \\
N-2 & 240 & 65 \\
N-3 & 440 & 100 \\
N-4 & 480 & 103 \\
Operated & & \\
Fx-8 dorsal & 320 & 84 \\
Fx-9 unilateral & 440 & 106
\end{tabular}

\begin{tabular}{crl} 
Fornix $(n=6)$ & & \\
Fx-7 & 280 & 60 \\
Fx-6 & 480 & 85 \\
Fx-1 & 440 & 88 \\
Fx-2 & 480 & 88 \\
Fx-3 & 440 & 94 \\
Fx-4 & 400 & 96 \\
& & \\
Hippocampal $(n=6)$ & & \\
H-5 & 640 & 155 \\
H-2 & 760 & 159 \\
H-4 & 720 & 167 \\
H-1 & 1120 & 216 \\
H-6 & 840 & 225 \\
H-3 & 1120 & 252 \\
H-7-Am & 1120 & 232 \\
\hline
\end{tabular}

phasize the long term deleterious effects of hippocampal removals on the monkeys' capacity to learn and retain multiple object-reward associations. 


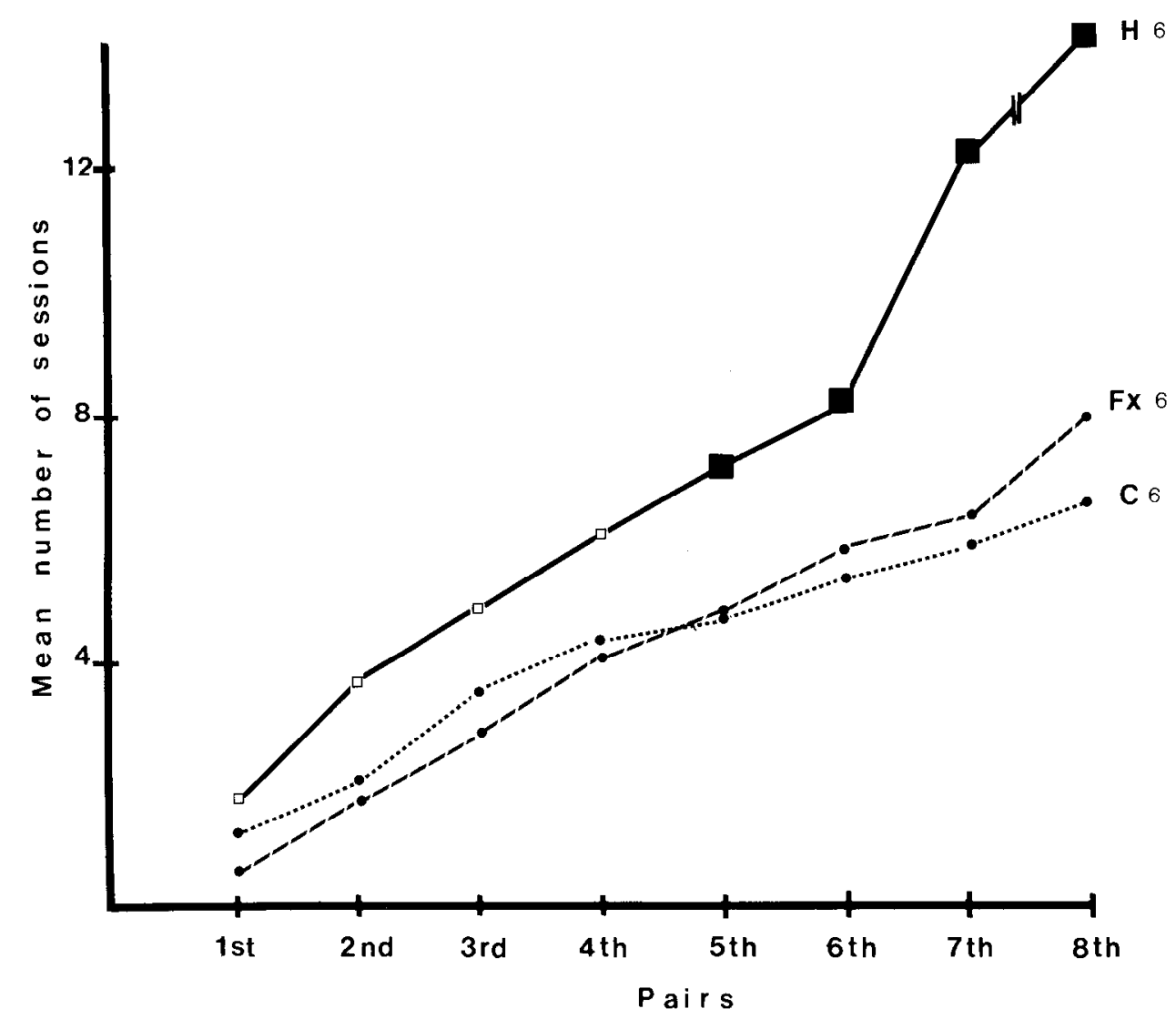

Figure 4. Experiment 1: Rates at which three groups of monkeys learned successively each of the eight discrimination problems presented concurrently. The larger solid symbols indicate significant differences from the control and fornix groups, respectively.

\section{Experiment 2a: Object Recognition TASK-Delays}

\section{Materials and Methods}

\section{Subjects}

The subjects were the same 19 monkeys that had taken part in experiment 1.

\section{Apparatus and procedure}

Monkeys were trained in the Wisconsin General Testing Apparatus to perform object recognition with raisins or small pieces of apple as the reward. The task assessed the monkeys' capacity to distinguish, after a single previous experience, a familiar from a novel object with increasing delays interposed between the presentation of the sample object and the recognition test trial.

Note. While the notion of the object recognition task as a well suited test of memory in monkeys is derived from Gaffan (1974), the procedure followed in the present study differed from his in one important respect and resembled closely that used recently by Mishkin (1978). The main modification consisted of substituting for the delayed matching-to-sample method used by Gaffan and delayed nonmatching-to-sample method. This change of procedure was based on an earlier finding by Mishkin and Delacour (1975) that monkeys learn faster with the nonmatching-to-sample method because it exploits their natural curiosity and readiness to respond to novel stimuli.
The basic task was administered as follows: a sample object was presented over the central food well of a tray containing three wells. The object was baited; that is, the monkeys could obtain the food reward by displacing it. Ten seconds later, the sample was re-presented together with a new object, with both objects placed over the two lateral wells. On the recognition trial, however, the sample was negative (not baited) and the novel object was positive (baited). After an intertrial interval of $20 \mathrm{sec}$, a different sample object was presented, followed $10 \mathrm{sec}$ later by another recognition trial. The position of the 2 objects varied, on successive test trials, from left to right lateral wells in a predetermined order (Gellerman, 1933) and a noncorrection procedure was used. Twenty trials a day were given until the monkeys reached a learning criterion of 90 correct responses in 100 consecutive trials or a maximum of 400 trials. Objects were drawn from a pool of 200 junk items, and each day, 40 of these were used in one session. The 200 objects were recombined randomly after every 100 trials to produce new sets of pairs, and 5 days of training would elapse before a given object was seen again by the monkeys.

Following the basic task, delays between the presentation of the sample and the test trials were increased, in stages, first to 30 , then to 70 and, finally to $130 \mathrm{sec}$. Twenty trials a day were given with 30 - and $70-$ sec delays and 10 trials a day were administered with delays of 130 
sec. In all, 140 trials were given with each of the three delays.

\section{Results}

Trial and error scores obtained by the three groups of monkeys on the basic task with 10-sec delays are shown in Table II. Control monkeys learned the task readily in 20 to 200 trials with an average of 28.7 errors.

Those in group Fx obtained comparable learning scores with 80 to 240 trials and a mean of 36.5 errors. However, only 3 of the 6 monkeys in group $H$ reached learning criterion within 200 trials. Of the remaining 3,2 needed twice as many trials and 1 was only able to attain $80 \%$ correct response levels within the limits of testing. Monkey H-7-Am also failed to learn the basic task and made only 60 correct responses in the last 100 trials.

The accuracy of performance with increased delays shown by control and operated monkeys is illustrated in Figure 5. Data obtained from individual monkeys with hippocampal ablations are presented in Table III. Both for purposes of illustration and for statistical analysis of the data, monkeys with hippocampal ablations were grouped according to their performance on the basic task:

TABLE II

Experiment 2a: Recognition task (delays); learning scores obtained by control and experimental groups on the basic task

Animals in the hippocampal group are coded numerically for the extent of hippocampal damage, with low variability in monkeys $\mathrm{H}-1$ to H-4. In H-7-Am, there was additional bilateral damage of the amygdala and area $\mathrm{TE}$.

\begin{tabular}{ccc}
\hline & \multicolumn{2}{c}{ Delay $(10 \mathrm{sec})$} \\
\cline { 2 - 3 } Group & Trials & Errors \\
\hline Control $(n=6)$ & & \\
Normal & 20 & 7 \\
N-1 & 40 & 10 \\
N-4 & 120 & 42 \\
N-2 & 200 & 46 \\
N-3 & & \\
Operated & 100 & 19 \\
Fx-8 dorsal & 100 & 48 \\
Fx-9 unilateral & & \\
& & \\
Fornix $(n=6)$ & 100 & 15 \\
Fx-2 & 80 & 18 \\
Fx-7 & 100 & 27 \\
Fx-6 & 220 & 43 \\
Fx-4 & 240 & 46 \\
Fx-3 & 200 & 70 \\
Fx-1 & & \\
& & \\
H-3 & & 35 \\
H-4 & 400 & 48 \\
H-5 & & \\
H-1 & 100 & 90 \\
H-6 & & \\
H-1 & 200 & 90 \\
H-7-Am & 400 & \\
Hippocampal & & \\
\hline
\end{tabular}

\footnotetext{
${ }^{\alpha}$ Partial unilateral sparing.

${ }^{b}$ Monkey failed to learn the task ( 80 and 60 correct responses in last 100 trials for H-6 and H-7-Am, respectively).
}

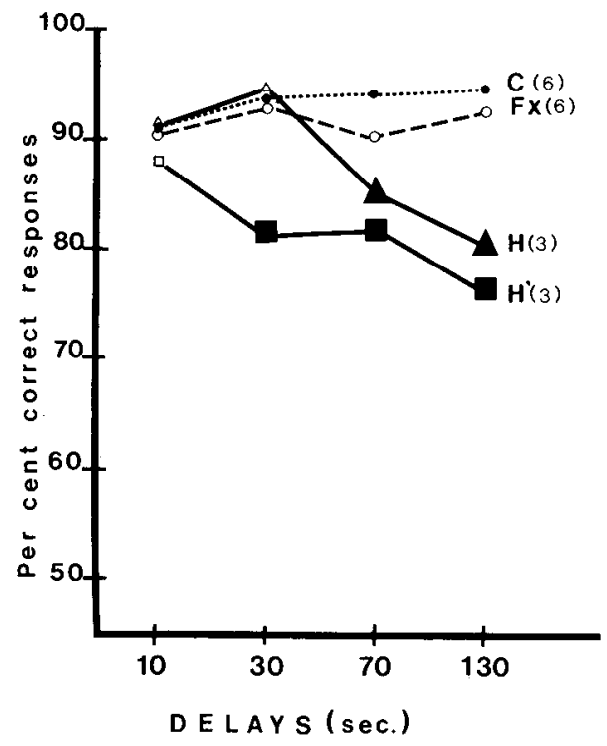

Figure 5. Experiment 2a: Mean group accuracy attained by four groups of monkeys on the recognition memory test. The larger solid symbols indicate significant differences from the control and fornix groups, respectively.

group $\mathrm{H}$, with 3 monkeys ( $\mathrm{H}-3, \mathrm{H}-4$, and $\mathrm{H}-5$ ) that had obtained normal learning scores, and group $\mathrm{H}^{\prime}$, which included 2 monkeys with elevated learning scores (H-1 and $\mathrm{H}-2)$ and $1(\mathrm{H}-6)$ that failed to learn the task (see Table II).

\section{Statistical comparisons}

Statistical comparisons were based on percentages of correct responses in the last 100 trials at each delay length. The data were analyzed by the use of a two-way analysis of variance, with groups as a "between subjects" factor and delays as a "within subject" factor. The analysis of variance was followed, when appropriate, by tests of simple main effects and by a posteriori comparisons using the Newman-Keuls paired comparisons test (Kirk, 1968).

Interaction effect. A significant interaction was found between delays and groups: $F(9,42)=4.77 ; p<0.0002$. Tests of simple main effects revealed no significant effects with 10-sec delays, the basic task: $F(3,56)=0.59$. However, effects were significant at all subsequent delays: $30 \sec , F(3,56)=8.57 ; p<0.01 ; 70 \sec F(3,56)=$ $8.38 ; p<0.01 ; 130$ sec, $F(3,56)=21.10 ; p<0.01$.

To determine the specific pattern of group differences at each of the three increased delays, between group comparisons were made by using the Newman-Keuls test. No significant differences were found between the performance of monkeys in the $\mathrm{C}$ and $\mathrm{Fx}$ groups at any of the delays. With 30-sec delays, the performance of monkeys in group $\mathrm{H}$ also did not differ significantly from that of monkeys in either group $\mathrm{C}$ or Fx. However, monkeys in group $\mathrm{H}^{\prime}$ performed at significantly lower levels of accuracy than did those in the other three groups ( $p$ values $<0.01$ ). With 70 -sec delays, monkeys in both the $\mathrm{H}$ and $\mathrm{H}^{\prime}$ groups, no longer significantly different from each other, attained significantly lower levels of accuracy than did those in group $\mathrm{C}$ or $\mathrm{Fx}$ ( $p$ values $<$ 
TABLE III

Experiments $2 a$ and $2 b$ : Lesion size and degree of impairment of monkeys with hippocampal resections on the recognition memory task

Monkeys H-1, -4, -3, and -2 sustained a radical bilateral hippocampectomy. The abbreviations used in the table are: TE, inferotemporal neocortex; Am, amygdala; Ent, entorhinal area; T.S., temporal stem; Bil, bilateral removal; Un, unilateral removal. The size of unilateral or bilaterally symmetrical lesions is indicated by: s, small; m, moderate; ext, extensive.

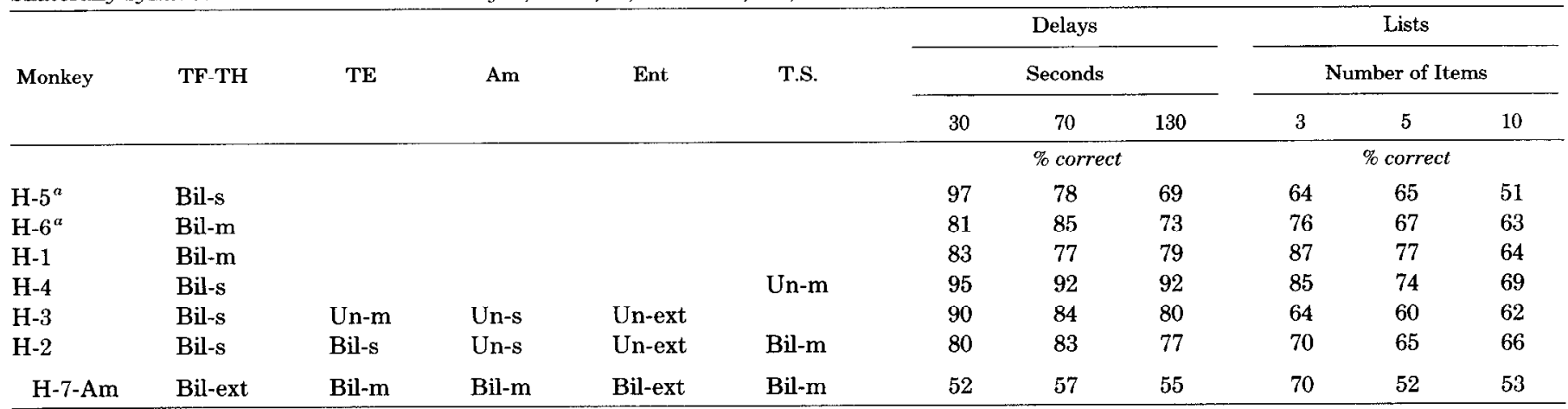

${ }^{a}$ Partial unilateral sparing of the hippocampus.

0.01). With 130-sec delays, a similar pattern of group differences was found: monkeys in groups $\mathrm{H}$ and $\mathrm{H}^{\prime}$, not significantly different from each other, performed significantly worse than did those in either group $\mathrm{C}$ or $\mathrm{Fx}$ ( $p$ values $<0.01$ ). The performance of monkey H-7-Am remained at chance levels at all delay lengths (see Table III).

Main effects. The detailed results obtained with the Newman-Keuls tests given above account for the significant main effects for groups: $F(3,14)=16.88 ; p<0.0001$, and for delays: $F(9,42)=6.71 ; p<0.0008$.

Summary. Monkeys with hippocampal ablations, but not those with sections of the fornix, were impaired significantly on the object recognition task with delays. This impairment was particularly noticeable when longer delays were interposed between the presentation of the sample object and the test of recognition. Additional unilateral or bilateral damage to area $\mathrm{TE}$ in combination with unilateral damage to the amygdala and entorhinal area did not result in a more accentuated impairment than did lesions confined to the hippocampus and cortical area TF-TH. However, monkey H-7-Am, with combined amygdalohippocampal damage and bilateral lesions of area TE and the entorhinal cortex, performed at chance levels at all delay lengths.

\section{Experiment 2b: Object Recognition TASK-Lists}

\section{Materials and Methods}

\section{Subjects}

The subjects were the same 19 monkeys that had taken part in the two previous experiments.

\section{Apparatus and procedure}

The apparatus was the same as that used in the two previous experiments. As in the delay version of the task, monkeys had to distinguish, after a single previous experience, a familiar from a novel object (i.e., between one previously presented or not presented). However, this time, instead of increasing the delays between the presentation of a single sample object and its pairing with a novel one, the number of objects presented for familiar- ization increased, in stages, first from 1 to 3 , then to 5 , and finally to 10 objects presented serially (lists of 3,5 , and 10 items). Then, each of the list items was presented singly with a novel object.

Monkeys were first retrained for 30 trials on the basic, 10 -sec delay task with a single object as the sample. If they did not make at least 27 correct responses, they were given an additional day of training. This was followed, on the next day (day 1), by another session with a list of 1 .

Lists of 3 . On the following day (day 2), 3 different objects were presented serially over the central food well at 10 -sec intervals. Twenty seconds after the presentation of the last item, each of the 3 objects was re-presented at 10-sec intervals, paired with a novel object, in the same order in which the list items had been first presented. Ten sets of lists of 3 were used in one session of 30 trials.

Lists of 5 . On day 3, the same procedure was used with 5 sample objects and six sets of lists of 5 were used in one session.

Lists of 10 . On day 4, 10 sample objects were presented serially, with three sets of lists of 10 used in one session.

The pool of 200 objects that had been used in experiment $2 \mathrm{a}$ was recombined every 90 trials. The 4 days constituted a block, with four blocks given in all, so that monkeys were given 120 trials with each of the four list lengths. The delays between the presentation and the representation of each list item were roughly comparable to the delays used in experiment $2 \mathrm{a}$. With the time taken to respond on each of the sample presentation trials (approximately $3 \mathrm{sec}$ ), they were $49 \mathrm{sec}$ for lists of 3 and 75 and 140 sec for lists of 5 and 10 items, respectively.

\section{Results}

\section{Accuracy of Performance}

\section{Lists of 1}

Monkeys in groups $\mathrm{C}$ and $\mathrm{Fx}$ made the correct response in $90 \%$ to $95 \%$ of the trials. As can be seen in Table IV, only 2 monkeys in group $\mathrm{H}(\mathrm{H}-4$ and $\mathrm{H}-1)$ attained a comparable level of accuracy. The remaining 4 monkeys 
TABLE IV

Experiment 2b: Recognition task (lists); performance of monkeys in the control and experimental groups on lists of 1 item in all four blocks (120 trials)

Animals in the hippocampal group are coded numerically for the extent of hippocampal damage, with low variability in monkeys $\mathrm{H}-1$ to H-4. In H-7-Am, there was additional bilateral damage of the amygdala and area TE. Monkeys in each group are ordered with respect to the percentage of correct responses.

\begin{tabular}{cc}
\hline Group & Percent Correct Responses \\
\hline Control $(n=6)$ & \\
Normal & 95 \\
N-1 & 91 \\
N-2 & 91 \\
N-3 & 90 \\
N-4 & \\
Operated & 90 \\
Fx-8 dorsal & 90 \\
Fx-9 unilateral & \\
& \\
Fornix $(n=6)$ & 91 \\
Fx-4 & 90 \\
Fx-1 & 90 \\
Fx-2 & 90 \\
Fx-3 & 90 \\
Fx-6 & 90 \\
Fx-7 & \\
& \\
H-4 & 92 \\
H-1 & 90 \\
H-2 & 85 \\
H-6 ${ }^{a}$ & 85 \\
H-3 & \\
H-5 & \\
H-7-Am & \\
\hline
\end{tabular}

${ }^{a}$ Partial unilateral sparing.

were able to respond correctly in only $77 \%$ to $85 \%$ of the trials. Monkey $\mathrm{H}-7-\mathrm{Am}$ gave $67 \%$ correct responses.

\section{Lists of 3, 5, and 10 items}

The accuracy of performance with longer lists shown by control and operated monkeys is illustrated in Figure 6. Data obtained from individual monkeys with hippocampal ablations are presented in Table III. For purposes of statistical analysis of the data, monkeys with hippocampal ablations were grouped according to their performance with lists of 1: group $\mathrm{H}$, with 2 monkeys ( $\mathrm{H}-1$ and $\mathrm{H}-4$ ) that performed with normal accuracy, and group $\mathrm{H}^{\prime}$, which included 4 monkeys $(\mathrm{H}-2, \mathrm{H}-3, \mathrm{H}-5$, and $\mathrm{H}-6)$ that were not able to re-attain $90 \%$ correct response levels.

\section{Statistical comparisons}

The data were analyzed by the use of a two-way analysis of variance, with groups as a "between subjects" factor and lists as a "within subjects" factor. This was followed, when appropriate, by tests of simple main effects and by a posteriori comparisons using the NewmanKeuls paired comparisons test. All analyses were based on percentages of correct responses out of a total of 120 trials.
Interaction effect. An analysis of variance revealed a significant interaction between lists and groups: $F(9,42)$ $=2.66 ; p<0.016$. Tests of simple main effects revealed significant effects at each list length: lists of $1, F(3,56)$ $=3.98 ; p<0.05$; lists of $3, F(3,56)=10.72 ; p<0.01$; lists of $5, F(3,56)=10.23 ; p<0.01$; lists of $10, F(3,56)=16.10$; $p<0.01$.

To determine the specific pattern of differences for each list length, the groups were compared by using the Newman-Keuls test. On lists of 1 , the basic task, monkeys in the $\mathrm{H}^{\prime}$ group made significantly more errors than did those in the other three groups ( $p$ values $<0.01$ ). With lists of 3 , a similar pattern of group differences was obtained, with all $p$ values $<0.01$. On lists of 5 , the performance of monkeys in group $\mathrm{H}^{\prime}$ continued to differ significantly from that of monkeys in the other three groups ( $p$ values $<0.01$ ). However, for the first time, the $2 \mathrm{H}$ monkeys ( $\mathrm{H}-1$ and $\mathrm{H}-4)$ made significantly more errors than did those in group $\mathrm{C}(p<0.05)$ though not significantly more than did monkeys in group Fx. With lists of 10, the performance of monkeys in groups $\mathrm{H}$ and $\mathrm{H}^{\prime}$, no longer significantly different from each other, continued to differ significantly from that of monkeys in group $\mathrm{C}$ or $\mathrm{Fx}(p$ values $<0.01)$.

In the delay version of the task, the performance of monkeys in the control group remained at consistently stable levels of accuracy which ranged from $90 \%$ to $98 \%$ correct responses. However, as list lengths increased from 1 to 10 items, Friedman's two-way analysis of variance (Siegel, 1956) revealed a corresponding and significant decrease in the accuracy of response in the control group $\left(\psi^{2}=14.60 ; p<0.01\right)$. Comparisons between any two list lengths, using Wilcoxon's matched pairs signed ranks test, revealed significant differences ( $T$ values $=0 ; p$ values < 0.05 ; two tailed) in all cases, except between lists of 5 and 10 items (Fig. 3). Therefore, it became of interest to compare the rates at which the accuracy of

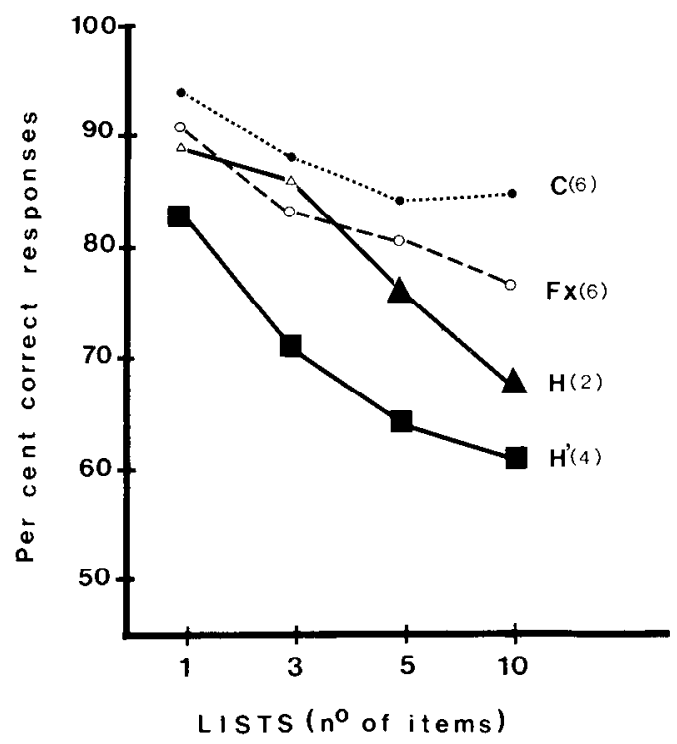

Figure 6. Experiment 2b: Mean group accuracy attained by four groups of monkeys on the recognition memory test. The larger solid symbols indicate significant differences from the control group at all list lengths and from the fornix group on lists of 1,3 , and 10 items. 
performance shown by control and operated monkeys declined. This was done by first determining, the difference between the percentage of correct responses on lists of 1 and on each of the three succeeding list lengths within each group. Then, the Newman-Keuls test was applied to these difference scores. The following pattern emerged: the difference between lists of 1 and 3 was significantly greater for the 4 monkeys in group $\mathrm{H}^{\prime}$ than it was for the other three groups ( $p$ values $<0.05$ ), which did not differ significantly from each other. Similarly, with lists of 5 , the decrease in accuracy from lists of 1 shown by $\mathbf{H}^{\prime}$ monkeys was greater than that shown by monkeys in the other three groups $(p<0.05)$. However, the decrease in accuracy shown by the 2 monkeys in group $\mathrm{H}$ did not differ significantly from that shown by monkeys in either group $\mathrm{C}$ or $\mathrm{Fx}$, which did not differ significantly from each other. Finally, with lists of 10 , the decrease in accuracy shown by $\mathbf{H}^{\prime}$ monkeys continued to differ significantly from that shown by either the $\mathrm{C}$ or $\mathrm{Fx}$ group values $(p<0.05)$. For the first time, however, the $2 \mathrm{H}$ monkeys showed a significantly greater decrease in accuracy than did monkeys in either group $\mathrm{C}$ or $\mathrm{Fx}(p$ values $<0.05$ ). In addition, $\mathrm{Fx}$ monkeys showed a significantly greater decrease in accuracy of performance than did those in group $\mathrm{C}(p<0.05)$. It should be noted, however, that the performance of 2 of the 6 monkeys in group Fx contributed to this difference.

Main effects. The detailed description of the results obtained with Newman-Keuls tests accounts for the significant main effects for groups: $F(3,14)=14.58$; $p<$ 0.0001 , and list length: $F(3,42)=54.32 ; p<0.00001$.

\section{Analysis of Error Patterns}

The serial presentation of several object samples which preceded tests of recognition may have resulted in pro- and retroactive interference between items. Since monkeys with hippocampal removals are particularly sensilive to interference in associative learning (Moss et al., 1981; experiment 1 in the present study), it was decided to examine the extent to which interference effects could have contributed to the impairment of monkeys in the hippocampal group on the recognition task.

Accordingly, the patterns of errors made on separate items in lists of differing lengths were analyzed in the following manner: the mean percentages of errors were computed for each group, for the first, middle, and last items, for lists of 3 and 5 items (i.e., items 1, 2, and 3 for lists of 3 and items 1, 3, and 5 for lists of 5). For lists of 10 , the mean percentages of errors were computed for items 1, 6 and 7, and 10. These data, plotted in Figures 7 and 8 , were analyzed by the use of tests of simple main effects which revealed significant group effects for all items tested except for the first items.

Note. The monkey in the hippocampal group (H-5) that had the most difficulty with all list lengths adopted a left position preference beginning with lists of 5 . Monkey Fx-1 adopted sporadically either left or right position preferences when given lists of 10 items. Therefore, the data obtained by the 2 animals could not be included in the statistical analysis of error patterns.

Analyses of variance were followed by tests of significance between groups using Tukey's HSD a posteriori test (Kirk, 1968). Detailed results are summarized in Table $\mathrm{V}$ which focuses on the differences in performance between monkeys in group $\mathrm{H}^{\prime}$ that performed significantly worse with lists of 1 and monkeys in the other three groups.

No significant differences were found between the performance of monkeys in groups $\mathrm{Fx}$ and $\mathrm{C}$ at any of the list lengths, nor were there any significant group differences on the 1st items at any of the list lengths. With

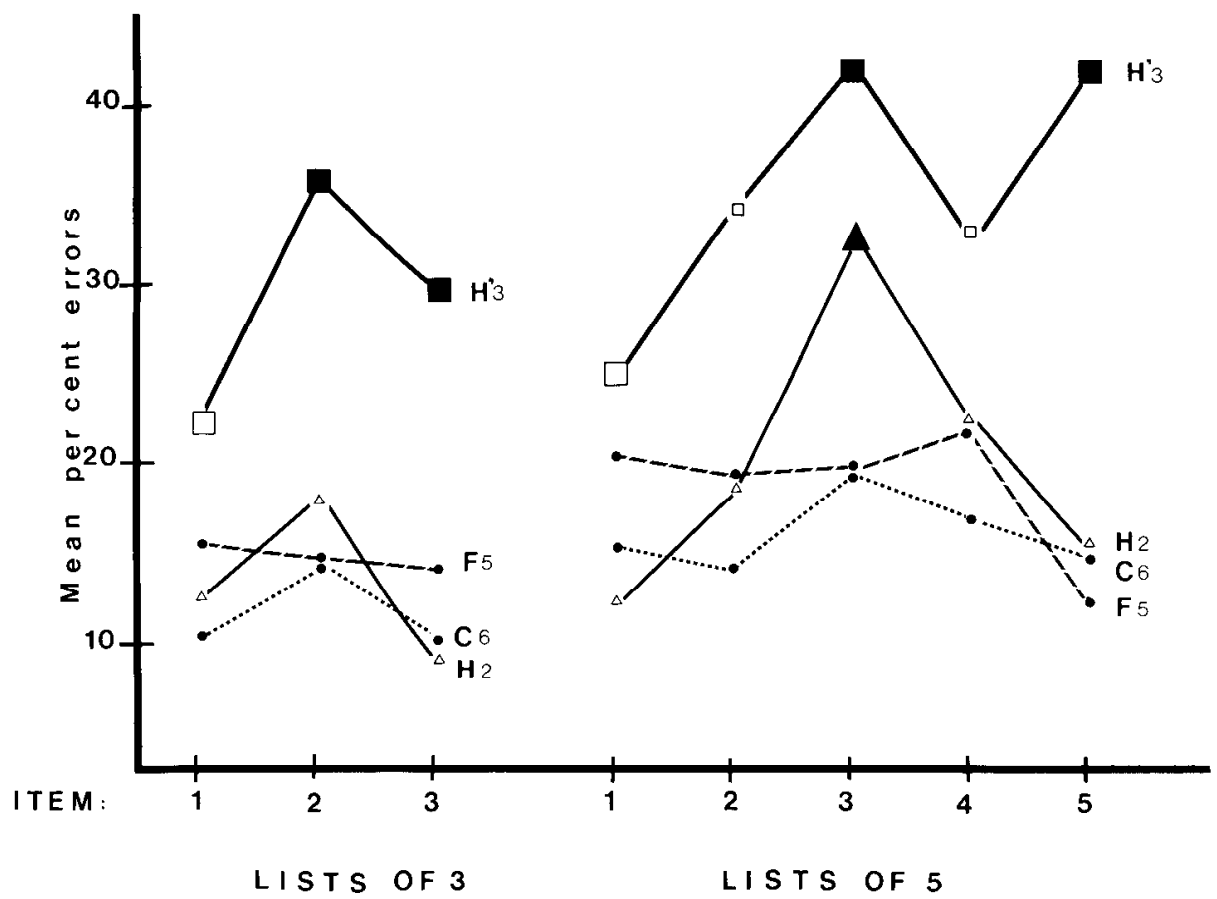

Figure 7. Experiment 2b: Pattern of errors made by four groups of monkeys on the recognition memory task with lists. The larger symbols indicate items analyzed statistically. The solid symbols indicate significant differences from the control and fornix groups, respectively. 


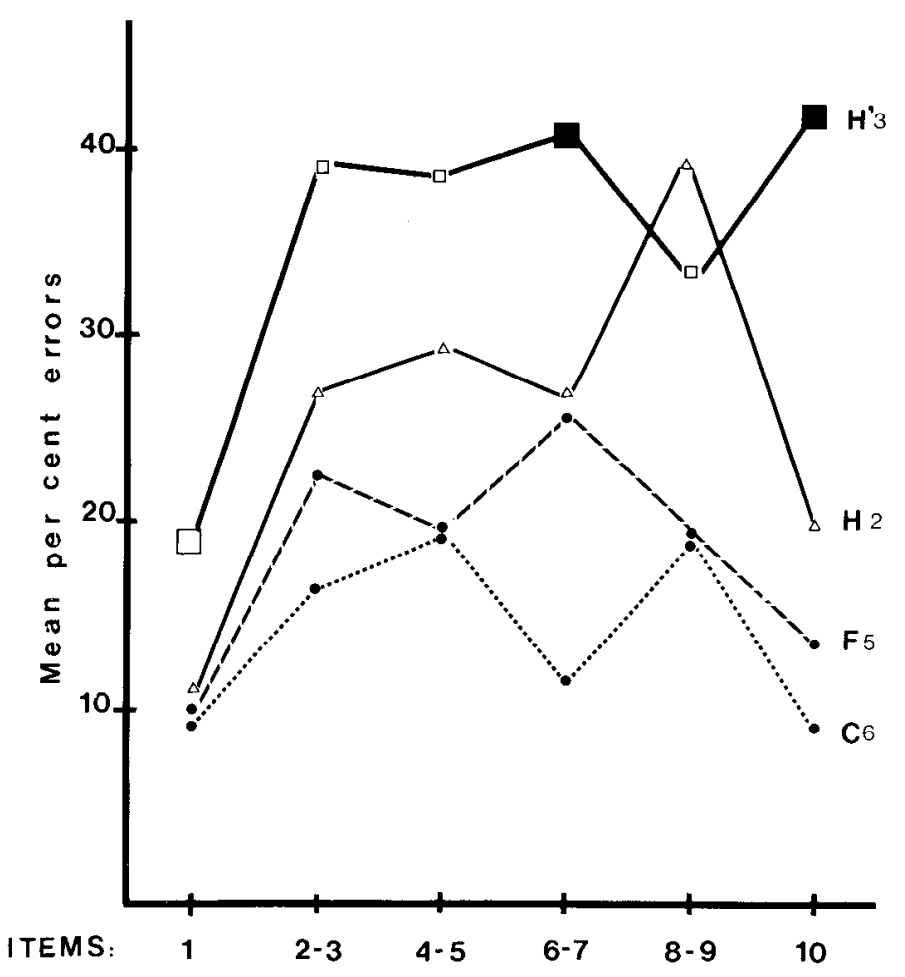

LISTS OF 10

Figure 8. Experiment 2b: Pattern of errors made by four groups of monkeys on the recognition memory task with lists. The larger symbols indicate items analyzed statistically. The solid symbols indicate significant differences from the control group on items 6 and 7 and 10 and from the fornix group on item 10. lists of 3 , monkeys in group $\mathrm{H}^{\prime}$ made significantly more errors on the 2nd and 3rd items than did those in the other three groups, which did not differ significantly from each other. With lists of 5 , monkeys in both the $\mathrm{H}$ and $\mathrm{H}^{\prime}$ groups, no longer significantly different from each other, made more errors on the 3rd item than did those in either group $\mathrm{C}$ or Fx. On the last, 5th item, monkeys in group $\mathbf{H}^{\prime}$ made significantly more errors than did those in the other three groups which did not differ significantly from each other. With lists of 10 , monkeys in group $\mathrm{H}^{\prime}$ made significantly more errors on the 6th and 7th items than did those in group $\mathrm{C}$ but not those in group $\mathrm{Fx}_{\mathrm{x}}$ or $H$. However, the performance of monkeys in the latter two groups did not differ significantly from that of monkeys in group C. On the last, 10th, item monkeys in group $\mathrm{H}^{\prime}$ made significantly more errors than did those in the other three groups, which did not differ significantly from each other.

Summary. Monkeys with hippocampal resections, but not those with fornix sections, were impaired in recognition when sample objects were presented serially in lists of different lengths, either at all list lengths (group $\mathrm{H}^{\prime}$ ) or on lists of 5 or 10 items (group H). Analysis of the pattern of errors on the first, middle, and last items at each list length revealed no impairment on the first items (intact primacy effect). However, monkeys with resections of the hippocampus made significantly more errors than did control monkeys either on the middle items or on both the middle and last items at all list lengths.

\section{Discussion}

The first of three principal findings was that monkeys with hippocampal ablations were impaired on both as-

TABLE V

Experiment 2b: Statistical comparisons among control and experimental groups based on the percent of errors made on the first, middle, and last items within three list lengths with a focus on the performance of monkeys in group $\mathrm{H}^{\prime}$

The abbreviations used in the table are: $\mathrm{C}$, control group; Fx, fornix group; $H$, monkeys with hippocampal damage that performed within control group limits of accuracy on "lists" of $1 ; \mathrm{H}^{\prime}$, monkeys that performed at lower than control group levels of accuracy.

\begin{tabular}{|c|c|c|c|c|c|c|c|}
\hline \multirow{2}{*}{ Lists of 3} & \multicolumn{7}{|c|}{ Item } \\
\hline & 1 & & 2 & & & 3 & \\
\hline$F$ ratios $(3,36)$ & n.s. ${ }^{a}$ & & $9.38^{b}$ & & & $6.97^{b}$ & \\
\hline Tukey's test & & $p<0.01$ & $p<0.01$ & $p<0.05$ & $p<0.05$ & $p<0.05$ & $p<0.01$ \\
\hline$F$ ratios $(3,36)$ & n.s, & & $5.93^{b}$ & & & $8.43^{b}$ & \\
\hline $\mathrm{H}^{\prime}$ versus & & $\mathrm{C}$ & $F x$ & $\mathrm{H}$ & $\mathrm{C}$ & $\mathrm{Fx}$ & $\mathbf{H}$ \\
\hline Tukey's test & & $p<0.05$ & $p<0.05$ & n.s. & $p<0.01$ & $p<0.01$ & $p<0.05$ \\
\hline Lists of 10 & \multicolumn{7}{|c|}{ Item } \\
\hline $\mathrm{H}^{\prime}$ versus & & $\mathrm{C}$ & $F x$ & $\mathbf{H}$ & $\mathrm{C}$ & $\mathbf{F x}$ & $\mathbf{H}$ \\
\hline Tukey's test & & $p<0.05$ & n.s. & n.s. & $p<0.01$ & $p<0.05$ & $p<0.05$ \\
\hline
\end{tabular}

${ }^{a}$ n.s., not significant.

${ }^{b} p<0.01$.

${ }^{c} p<0.025$. 
sociative learning and recognition memory tasks and that they were abnormally sensitive to pro- and retroactive interference. The second was that sections of the fornix were not followed by corresponding behavioral deficits. The third was that hippocampal damage has long term disruptive effects on learning and memory in the monkey. The three findings will be discussed under separate headings.

\section{Hippocampal Defects}

\section{Associative learning task}

Results of concurrent discrimination task. The results obtained with the concurrent discrimination task in experiment 1 replicated those found in an earlier study by Moss et al. (1981). First, both normative data and the degree of impairment shown by operated monkeys were comparable in the two studies: 4 normal, control monkeys of the Moss et al. (1981) study learned the task in the visual modality in 240 to 480 trials with 81 to 120 errors, while 7 monkeys with hippocampal ablations learned it in 640 to 1200 trials with 159 and 373 errors. Closely similar learning scores were obtained in the present study by monkeys in the control and hippocampal groups (Table I).

Second, with concurrent presentation, associations between reward and given stimulus objects have to be acquired in the presence of proactive and retroactive interpair interference to which, as shown in control experiments by Moss et al. (1981) monkeys with hippocampal ablations were abnormally sensitive. In the present study, detailed analysis of day-by-day performance on the concurrent discrimination task, similar to that described by Moss et al. (1981), revealed that control monkeys learned to discriminate several pairs simultaneously and that, once learned, the discriminations were well retained. In contrast, monkeys with hippocampal ablations learned the eight discriminations with long intervening pauses and frequently made errors on previously learned discriminations. Interestingly, the point at which the effects of interference began to affect significantly the performance of operated monkeys in the study by Moss et al. (1981) depended, in part, on their experimental history: relatively naive monkeys learned with normal ease only the first three pairs and took significantly longer than did normal monkeys to learn each of the remaining five pairs. More sophisticated monkeys had marked difficulty only with the last three pairs. It was not surprising, therefore, to see in the present study that highly sophisticated operated monkeys were most retarded in learning the last of the eight pairs (Fig. 4).

However, it should be noted that, though ablations of the hippocampal formation result in enhanced sensitivity to interference in both visual and tactual modalities (Moss et al., 1981), they also can result in impairment on associative tasks other than those which provide interpair interference. Thus, as mentioned in the introduction, impaired retention of visual two-choice object discriminations was found after delays of either 1-, 24-, or 48-hr (Mahut et al., 1981). In addition, deficits have been found on simple two-choice visual discrimination tasks: in the study by Moss et al. (1981), individual operated monkeys obtained elevated error scores on brightness and hue discriminations and were impaired significantly as a group on a pattern discrimination task (square versus cross). This deficit was present even though none of the operated monkeys had sustained additional ablations of the anterior inferotemporal neocortex which, alone, are sufficient to disrupt visual discrimination learning (for reviews, see Gross, 1973; Dean, 1976).

Taken together, existing evidence reveals that both impaired learning and long term retention of object-reward associations, in more than one modality, are among the behavioral deficits which reliably follow resections of the hippocampal formation in the monkey.

Anatomical considerations. Before impairment on the concurrent discrimination task can be attributed confidently to damage of the hippocampus, the possible role of damage to extrahippocampal structures needs to be considered. In 3 of the 6 monkeys, ablations were confined to Ammon's horn, the dentate fascia, the subicular complex, and area TF-TH. However, 3 others sustained, in addition, either unilateral or bilateral damage of the anterior inferotemporal neocortex (area TE), temporal stem, amygdala, and parahippocampal cortices (Table III). Ablations of area TE alone are known to retard learning of the concurrent discrimination task (Iwai and Mishkin, 1968; Cowey and Gross, 1970; Moss et al., 1981). Yet, no systematic relationship could be found in the present study between the size of the lesion and performance, with both the lowest and highest error scores obtained by monkeys with ablations confined to the hippocampus and area TF-TH. Even H-7-Am, the monkey with the largest lesion that included bilateral ablation of both area TE and amygdala, obtained the same trial score as did monkey $\mathrm{H}-1$, without area TE damage, and made only 7 errors more than did monkey $\mathrm{H}-6$, with partial unilateral sparing of hippocampus and no damage of area TE. If, in addition, one takes into account that 4 of the 8 monkeys with resections of the hippocampus in the study by Mahut et al. (1981) had either minimal or no damage of area TE and that none of the 7 monkeys in the study by Moss et al. (1981) had sustained extrahippocampal damage other than that to area TF-TH, it appears that resection of the hippocampus, without additional damage to area TE, is sufficient to disrupt learning and retention of object-reward associations.

\section{Recognition memory}

Degree of impairment. Monkeys with hippocampal ablations were impaired significantly on the recognition task when delays were interposed between presentations of sample objects and test trials (experiment 2a). However, the degree of impairment was not uniform within the group: 3 monkeys learned the basic task within the normal range of trials and errors, and of these, 1 remained unimpaired (H-4) and $2(\mathrm{H}-3$ and $\mathrm{H}-5)$ were impaired only with the two longest delays; the remaining 3 monkeys were impaired both on the basic task and at all three delays (Tables II and III). On the whole, the degree of impairment was relatively mild, with group means of $83 \%$ and $78 \%$ correct responses found at the two longest delays, respectively.

A significant deficit also was found when sample objects were presented in lists of 3,5 , and 10 items (experiment $2 \mathrm{~b}$ ). As was the case with delays, the degree of impairment was not uniform within the group (Tables 
III and IV): 2 monkeys were impaired only with lists of 5 and 10 items, while 4 others were impaired at all list lengths. Both control monkeys and those with hippocampal ablations performed less accurately on lists than they did on delays. However, while the performance of control monkeys remained consistently at or above $80 \%$ correct response levels, that of operated monkeys declined to chance levels as a function of list length.

The relatively greater difficulty experienced by all monkeys on lists as compared with delays was unexpected, and in addition, two salient aspects of the performance of monkeys with hippocampal ablations had to be explained. First, 4 of the 6 were unable to re-attain $90 \%$ correct response levels with "lists of 1 ," a control condition identical to the basic task with 10-sec delays on which at least 3 of the 4 had performed with normal accuracy in the preceding experiment (Tables II and IV). Second, H-4, the only unimpaired monkey on delays, was nevertheless impaired on lists (Table III). These findings, which raised the possibility that the two versions of the recognition task may not have been functionally equivalent, became easier to interpret after an examination of error patterns on the list test.

Pattern of errors made on individual list items. Control monkeys retained equally well the first and last items at all list lengths and, by inspection, made more errors only on some of the intermediate items in lists of 5 and 10 items (Figs. 7 and 8). Two operated monkeys (group H) showed a similar pattern of performance except that they made significantly more errors than did control monkeys on the middle items in lists of 5 and, by inspection, on intermediate items in lists of 10 . However, the pattern of crrors made by 3 other monkeys (group $\mathrm{H}^{\prime}$ ) was in sharp contrast: while their recognition of the first items was unimpaired (intact primacy effect), they made significantly more errors than did control monkeys not only on the middle items but also on the last items at all list lengths. Thus, all monkeys with resections of hippocampus were sensitive to pro- and retroactive interference, but abnormally poor retention of the last items by some operated monkeys suggests a greater susceptibility to proactive interference.

Yet, within list interference, provided by serial presentation of several items, may have constituted only one source of difficulty. Conceivably, due to the order of presentation of the two tasks (delays followed by lists) and to the relatively limited size of the pool of objects, across task interference may have been another source of difficulty. The pool of objects used with lists contained the same 200 objects that had been used previously with delays. This means that, at the start of the list test, individual monkeys had seen each object both as sample and test items between 7 and 12 times. As repeated presentation of the same objects increased over the subsequent four blocks of 120 trials with each list length, it may have provided increasing proactive interference. As a result, on each nonmatching test trial with lists, monkeys may have experienced progressively greater difficulty in deciding whether a test item had been seen or not seen before.

Indirect support for the notion that the size of the pool of objects may have played a role in performance on the list test comes from a study by Sands and Wright (1980): a normal rhesus monkey was given a recognition task with lists of 3 items (color photographs). When, in order to provide low interference levels, the pool consisted of 211 items, the monkey was able to make correct identifications ("same" or "different") on 93\% of the trials. However, when 3-item lists were drawn from a pool of the same 6 items, the overall accuracy of recognition dropped to $79 \%$ correct responses. Similarly, a decrease in accuracy was observed in 3 other normal monkeys when the same pair of objects was used throughout each daily session of 30 trials in a nonmatching-to-sample recognition task (Owen and Butler, 1981). Possibly, postoperative impairment on the list test could be alleviated by using a pool of objects large enough to make the task a truly trial-unique test of memory.

If correct, the notions of within and across task interference would help account for the slightly lower accuracy of performance by control monkeys on lists as compared with delays. It would, especially, account for the unexpected inability of 3 operated monkeys to reattain $90 \%$ correct response levels on lists of 1 in experiment $2 \mathrm{~b}$ and for the selective deficit on lists shown by monkey $\mathrm{H}-4$, without accompanying impairment on delays. Taken together, the evidence obtained in experiments $2 a$ and $2 b$ suggests that, while the delay test may have assessed primarily anterograde effects of hippocampectomy on the rate of decay of memory traces, the list test may have assessed interactive effects between the capacity to maintain memory traces over time and interference.

The impairment on the recognition task, particularly severe on the list version (Table III), is at variance with the absence of impairment or mild impairment reported by Mishkin (1978). Yet, in both studies, the same nonmatching-to-sample procedure was used with comparable delays and the same list lengths. The discrepancy between the two sets of results is puzzling, particularly since monkeys in the present study were considerably more sophisticated experimentally than were those tested by Mishkin (1978). Also, ablations sustained by 4 of the 6 monkeys in our hippocampal group seem to correspond to the ablations in 2 of Mishkin's 3 monkeys with intended selective ablations of the hippocampal formation. The difference could be due, perhaps, to the fact that, while the present study assessed anterograde effects of hippocampal damage, the results reported by Mishkin (1978) reflect the extent of postoperative retention of a preoperatively learned task. Of some importance may have been also the apparently larger pool of objects used by Mishkin (1978).

Anatomical considerations. (a) Due to the surgical approach to the hippocampus, all 6 monkeys in the hippocampal group sustained bilateral damage of area TF-TH. Though its main projection target, the hippocampal complex including the subiculum (Van Hoesen et al., 1979), was ablated, this area also has been found to project to the amygdala either directly (Aggleton et al., 1980) or indirectly through the perirhinal (Van Hoesen and Pandya, 1975) or entorhinal (Aggleton et al., 1980) cortices. However, these projections are sparse and appear to be limited to the lateral amygdaloid nuclei. Fur- 
thermore, bilaterally symmetrical damage of area TF. TH was, at most, moderate and the entorhinal area was spared in 4 of the 6 monkeys in the group (Table III). This makes it difficult to attribute the deficit shown by at least 4 monkeys, whose lesions were limited to the hippocampal complex and area TF-TH, to additional functional deafferentation of the amygdala.

Two of the 6 monkeys sustained inadvertent damage to extrahippocampal structures beyond area TF-TH. In $1(\mathrm{H}-2)$, there was some damage of area TE and this cortical area has been found to project directly to the lateral (Aggleton et al., 1980), basal (Herzog and Van Hoesen, 1976), or both lateral and basal (Turner et al., 1980) amygdaloid nuclei. However, bilateral damage to area TE was small and asymmetrical. The same monkey also had sustained moderate, but bilateral, damage of the temporal stem and a suggestion has been made that damage to this structure, rather than that to the hippocampus, may be responsible for memory deficits (Horel, 1978). However, the weight of the negative evidence makes this possibility unlikely (see Moss et al., 1981). Since only 2 monkeys sustained varying degrees of damage to more than one extrahippocampal structure (area TF-TH), the possible interactive effects of even unilateral lesions of the amygdala, entorhinal cortex, and area TE with those of bilateral, radical ablations of the hippocampal complex and partial bilateral ablations of area TF-TH cannot be assessed. However, the performance of monkeys in the hippocampal group did not appear to reflect individual differences in the size or locus of lesion (Table III).

(b) On lists, bilateral ablations confined to the hippocampal complex and area TF-TH disrupted performance of some animals almost as effectively as did the ablation which included bilateral damage to the amygdala, area $\mathrm{TE}$, and entorhinal cortex in monkey H-7-Am. However, on delays, H-7-Am was the only operated monkey whose performance remained consistently at chance levels (Table III). The two subcortical projection targets (hippocampus and amygdala) of the entorhinal area were ablated and bilateral damage to area TE was moderate and limited to its ventral aspect. It should be noted that, in Mishkin's experiment (1978), 1 of the 3 monkeys with combined amygdalohippocampal removals sustained, in addition, a bilateral, asymmetrical lesion of the ventral aspect of area TE. All 3 monkeys were impaired significantly. Yet, except for the difficulty in relearning the initial task with 10-sec delays, the performance of this monkey on subsequent delays, or lists, was not worse than that of the other 2 monkeys. It appears, therefore, that the critical factor may have been the combined amygdalohippocampal removal.

Though the severity of the deficit shown by monkey H-7-Am on the recognition task is not a new finding (Mishkin, 1978), available behavioral evidence is far too incomplete to allow an understanding of the task-specific synergistic effects of an amygdalohippocampal ablation. First, there are exceptions: in an earlier study, it was found that when monkeys with resections of the hippocampus were not impaired on certain tasks, neither were those with amygdalohippocampal removals (Mahut, 1971). Second, combined ablations have been found to result in interactive effects on tasks other than those which assess recognition memory (Correll and Scoville, 1965; Mahut, 1971; Mahut et al., 1981). Third, though severely retarded, individual monkeys with amygdalohippocampal ablations have been found to reach learning criterion on certain tasks (spatial and object reversals and concurrent discrimination) if given sufficiently long training (Mahut, 1971; experiment 1 in the present study).

The synergistic effects of an amygdalohippocampal ablation on memory processes are easier to account for in the light of amygdalar connections with another brain structure implicated in memory functions. Pure anterograde amnesia for verbal material has been found in a patient (N. A.) to result from a left hemisphere lesion of the medial thalamus which includes the medial dorsal nucleus (Squire and Slater, 1978; Squire and Moore, 1979). Recently, projections from the amygdala to the medial dorsal thalamic nucleus, demonstrated earlier in the monkey with fiber degeneration methods (Nauta, 1961), have been confirmed with autoradiographic methods (Porrino et al., 1981). Possibly, the severe impairment shown by monkey H-7-Am on the recognition memory task with delays may have been due to the interruption of direct amygdalothalamic connections in addition to the ablation of the hippocampus. One of the first steps toward the understanding of the synergistic effects of an amygdalohippocampal ablation on memory would be to examine the effects of a medial dorsal thalamic lesion alone and in combination with an ablation of the hippocampus.

\section{Absence of Deficit after Fornix Transections}

Monkeys with sections of the fornix were not impaired on the concurrent discrimination task or on the two recognition memory tests, and the absence of impairment is compatible with the results of two previous studies (Moss et al., 1981; Mahut et al., 1981).

The unimpaired performance of monkeys in the fornix group on the recognition task is in sharp contrast with a significant impairment found by Gaffan (1974) when comparable delays and list lengths were used. However, though both studies examine anterograde effects of fornix damage, they are not directly comparable and important differences in method may be responsible for the discrepancy in the results. Monkeys in Gaffan's (1974) study seem to have been younger at the time of surgery than those that participated in the present study: while his monkeys weighed $2 \mathrm{~kg}$, those in the present study weighed between 2.7 and $3.4 \mathrm{~kg}$ and we found in a separate project that 24 rhesus macaque monkeys weighed $2 \mathrm{~kg}$ at about 330 days of age (S. Zola-Morgan and $\mathrm{H}$. Mahut, unpublished records). Furthermore, while Gaffan (1974) used a matching-to-sample procedure, a nonmatching-to-sample task was used in the present study. Finally, the monkeys in Gaffan's study were tested shortly after surgery, while, in the present study, recognition tests were given 5 years following surgery and intervening tests on different behavioral tasks.

The possibility of functional recovery cannot be ruled out in the present study, but it would have to be accepted with at least two reservations in mind. First, one would 
have to assume that recovery was specific to memory, since immediately prior to the present study, the performance of monkeys in the fornix group differed significantly from that of monkeys in either normal or hippocampal groups on a test of preference for pcrceptual novelty in two modalities (Zola-Morgan et al., 1982). The second reservation is based on clinical findings. Although they frequently lack neuropsychological and neuropathological descriptions, clinical reports provide little support for the notion that fornix damage results in amnesia. More specifically, one of us (S. Z. -M.) has reviewed 50 cases in which the fornix had been disrupted either by neuropathology or by surgical intervention and found only three patients with reported memory defects. Two are still alive (Sweet et al., 1959; Heilman and Sypert, 1977) and damage to structures other than the fornix cannot be ruled out. In fact, Heilman and Sypert (1977) believe that their patient has additional damage to the hippocampal commissure. In the third case (Hassler and Reichert, 1957), the patient developed a high fever and died within 8 days of surgery. It is during this brief period that the patient did not remember having undergone surgery and was disoriented with respect to time; an autopsy revealed, in addition to the interrupted fornix, a unilateral tumor in the frontal lobe.

The absence of deficit on the recognition memory task after fornix section found in the present study is compatible with previous findings. So far, qualitatively equivalent results following fornix and hippocampal damage have been found only on a spatial task (i.e., left-right position reversals; Mahut, 1972; Mahut and Zola, 1973) and not on five nonspatial tasks (Mahut, 1972; Zola and Mahut, 1973; Moss et al., 1981; Mahut et al., 1981; ZolaMorgan et al., 1982). Taken together, all of the instances of functional dissociation between the two types of lesion caution against assuming safely that data obtained with sections of the fornix will always mirror the behavioral consequences of hippocampal ablations, at least in the monkey.

\section{Long Term Effects of Hippocampal Damage}

Monkeys that participated in the present study had sustained hippocampal damage at 2 years of age. The postoperative impairment found initially on the retention of object-reward associations after either 1-, 24-, or 48-hr intervals became attenuated or was absent when monkeys were tested on this task, for the third time, 2 years after surgery. However, when new tests of associative learning and memory were used in the present study, monkeys with ablations of the hippocampus were still impaired significantly 5 years following surgery and intervening experience with other behavioral tasks. It appears, therefore, that the attenuation of the initial postoperative impairment on the retention task reflected beneficial effects of practice rather than a recovery of learning and memory capacities and that hippocampal damage in the nonhuman primate can have long lasting disruptive effects on both associative and recognition memory.

\section{References}

Aggleton, J. P., M. J. Burton, and R. E. Passingham (1980) Cortical and subcortical afferents to the amygdala of the rhesus monkey (Macaca mulatta). Brain Res. 190: 347-368.

Corkin, S. (1965) Tactually-guided maze-learning in man: Effects of unilateral cortical excisions and bilateral hippocampal lesions. Neuropsychologia 3: 339-351.

Correll, R. E., and W. B. Scoville (1965) Performance on delayed match following lesions of medial temporal lobe structures. J. Comp. Physiol. Psychol. 60: 360-367.

Cowey, A., and C. G. Gross (1970) Effects of foveal prestriate and inferotemporal lesions on visual discrimination by rhesus monkeys. Exp. Brain Res. 11: 128-144.

Dean, P. (1976) Effects of inferotemporal lesions on the behavior of monkeys. Psychol. Bull. 83: 41-71.

Gaffan, D. (1974) Recognition impaired and association intact in the memory of monkeys after transection of the fornix. J. Comp. Physiol. Psychol. 86: 1100-1109.

Gellerman, L. W. (1933) Chance orders of alternating stimuli in visual discrimination experiments. J. Gen. Psychol. 42: 207208.

Gross, C. G. (1973) Visual functions of inferotemporal cortex. In Handbook of Sensory Physiology, R. Jung, ed., pp. 451482, Springer-Verlag, Berlin.

Hassler, R., and T. Reichert (1957) Über einen Fall von doppelseitiger Fornicotomie bei sogennanter temporaler Epilepsie. Acta Neurochir. (Wien) 5: 330-340.

Heilman, K. M., and G. W. Sypert (1977) Korsakoff's syndrome resulting from bilateral fornix lesions. Neurology (N. Y.) 27 : 490-493.

Herzog, A. G., and G. W. Van Hoesen (1976) Temporal nencortical afferent connections to the amygdala in the rhesus monkey. Brain Res. 115: 57-69.

Horel, J. (1978) The neuroanatomy of amnesia. A critique of the hippocampal memory hypothesis. Brain 101: 403-445.

Iwai, E., and M. Mishkin (1968) Two visual foci in the temporal lobe of monkeys. In Japan-US Joint Seminar on Neuro. physiological Basis of Learning and Behavior, Kyoto, Japan.

Kirk, R. E. (1968) Experimental Design: Procedures for the Behavioral Sciences, Brooks-Cole, Belmont, CA.

Mahut, H. (1971) Spatial and object reversal learning in monkeys with partial temporal lobe ablations. Neuropsychologia 9: 409-424.

Mahut, H. (1972) A selective spatial deficit in monkeys after transection of the fornix. Neuropsychologia 10: 65-74.

Mahut, H., and S. Zola (1973) A non-modality specific impairment in spatial learning after fornix lesions in monkeys. Neuropsychologia 11: 255-269.

Mahut, H., and S. Zola (1976) Effects of early hippocampal damage in monkeys. Soc. Neurosci. Abstr. 2: 829.

Mahut, H., and S. Zola (1977) Ontogenetic time-table for the development of three functions in infant macaques and the effects of early hippocampal damage upon them. Soc. Neurosci. Abstr. 3: 428 .

Mahut, H., S. Zola-Morgan, and M. Moss (1979) Retention deficits in monkeys after damage to the hippocampal system. The INS Bulletin, December, p. 12.

Mahut, H., M. Moss, and S. Zola-Morgan (1981) Retention deficits after combined amygdalo-hippocampal and selective hippocampal resections in the monkey. Neuropsychologia 19: 201-225.

Milner, B. (1972) Disorders of learning and memory after temporal lobe lesions in man. Clin. Neurosurg. 19: 421-446.

Milner, B. (1974) Hemispheric specialization: Scope and limits. In The Neurosciences: Third Study Program, F. O. Schmitt and F. G. Worden, eds., pp. 75-89, MIT Press, Cambridge, MA.

Mishkin, M. (1978) Memory in monkeys severely impaired by combined but not by separate removal of amygdala and hippocampus. Nature 273: 297-298.

Mishkin, M., and J. Delacour (1975) An analysis of short-term 
visual memory in the monkey. J. Exp. Psychol. (Anim. Behav.) 1: 326-334.

Moss, M., H. Mahut, and S. Zola-Morgan (1981) Concurrent discrimination learning of monkeys after hippocampal, entorhinal, or fornix lesions. J. Neurosci. 1: 227-240.

Nauta, W. J. H. (1961) Fibre degeneration following lesions of the amygdaloid complex in the monkey. J. Anat. 95: 515-531.

Orbach, J., B. Milner, and T. Rasmussen (1960) Learning and retention in monkeys after amygdala-hippocampus resection. Arch. Neurol. 3: 230-251.

Owen, M. J., and S. R. Butler (1981) Amnesia after transection of the fornix in monkeys: Long-term memory impaired, shortterm memory intact. Behav. Brain Res. 3: 115-123.

Penfield, W., and B. Milner (1958) Memory deficit produced by bilateral lesions in the hippocampal zone. Arch. Neurol. Psychiatry 79: 475-479.

Porrino, L., A. M. Crane, and P. S. Goldman-Rakic (1981) Direct and indirect pathways from the amygdala to the frontal lobe in rhesus monkeys. J. Comp. Neurol. 198: 121136.

Rehbein, L., S. Zola-Morgan, II. Mahut, and M. Moss (1980) Failure of sparing, or recovery, of recognition memory after early hippocampal resections in the rhesus macaque. Soc. Neurosci. Abstr. 6: 88.

Sands, S. F., and A. A. Wright (1980) Primate memory: Retention of serial list items by a rhesus monkey. Science 209: 938940.

Scoville, W. B. (1954) The limbic lobe in man. J. Neurosurg. 11: 64-66.

Scoville, W. B., and B. Milner (1957) Loss of recent memory after bilateral hippocampal lesions. J. Neurol. Neurosurg. Psychiatry 20: 11-21.

Siegel, S. (1956) Nonparametric Statistics for the Behavioral
Sciences, McGraw-Hill, New York.

Snider, R. S., and J. C. Lee (1961) A Stereotaxic Atlas of the Monkey Brain (Macaca mulatta), University of Chicago Press, Chicago.

Squire, L. R., and R. Y. Moore (1979) Dorsal thalamic lesion in a noted case of human memory dysfunction. Ann. Neurol. 6 : 503-506.

Squire, L. R., and P. C. Slater (1978) Anterograde and retrograde memory impairment in chronic amnesia. Neuropsychologia 16: 313-322.

Sweet, W. H., G. A. Talland, and F. K. Ervin (1959) Loss of recent memory following section of the fornix. Trans. Am. Neurol. Assoc. 84: 76-82.

Turner, B. H., M. Mishkin, and M. Knapp (1980) Organization of the amygdalopetal projections from modality-specific cortical association areas in the monkey. J. Comp. Neurol. 191: $515-543$.

Van Hoesen, G. W., and D. N. Pandya (1975) Some connections of the entorhinal (area 28) and perirhinal (area 35) cortices of the rhesus monkey. I. Temporal lobe afferents. Brain Res. 95: 1-24.

Van Hoesen, G. W., D. L. Rosene, and M. -M. Mesulam (1979) Subicular input from temporal cortex in the rhesus monkey. Science 205: 608-610.

von Bonin, G., and P. Bailey (1947) The Neocortex of Macaca mulatta, University of Illinois Press, Urbana, IL.

Zola, S., and H. Mahut (1973) Paradoxical facilitation of object reversal learning after transection of the fornix in monkeys. Neuropsychologia 11: 271-284.

Zola-Morgan, S., J. Da̧browska, M. Moss, and H. Mahut (1982) Enhanced preference for perceptual novelty in the monkey after sections of the fornix, but not after hippocampal ablations. Neuropsychologia, in press. 